\title{
The Constructionist as Claims-Maker? A Pragmatist Intervention into Social Problems Theory
}

\author{
Antony J. Puddephatt ${ }^{1}$ (1)
}

Accepted: 10 May 2021 / Published online: 18 June 2021

(c) The Author(s), under exclusive licence to Springer Science+Business Media, LLC, part of Springer Nature 2021

\begin{abstract}
In 1985, Steve Woolgar and Dorothy Pawluch wrote an influential essay about social constructionism, warning against the pitfalls of what they referred to as "ontological gerrymandering," which is to treat certain actors' claims as socially constructed, while at the same time making realist claims about social conditions. Instead of this unbalanced and asymmetric approach, the best way forward for constructionists is to treat all claims made by any and all acting parties as putative, not necessarily true or false, and to avoid making any independent claims about the actual social conditions that actors are striving to define. Since this time, social problems research, science and technology studies, and environmental sociology have encountered both epistemic and political difficulties with this strict constructionist approach to being fully agnostic about social conditions and the reality of actors' claims. Drawing on the social pragmatism of George Herbert Mead, I consider some of the problems encountered in the strict constructionist approach, and argue that ultimately, the sociologist herself cannot escape the general problem of having to make objective claims about the empirical social world. Instead of being agnostic about all claims made, sociologists are best to fully accept the responsibility and advantages of being full blown claimsmakers themselves.
\end{abstract}

\section{Introduction}

It is an honour to be invited to write an essay in dedication to Dr. Dorothy Pawluch, who retired recently from my alma mater, McMaster University, in Hamilton, Ontario, Canada. During my PhD studies there in the early 2000s, I benefitted greatly from many hours of conversations and friendly debates in her office. She was incredibly generous with her time and may well be the most pleasant person to chat with I have encountered. Our debates almost always turned

Antony J. Puddephatt

apuddeph@lakeheadu.ca

1 Professor of Sociology, Department of Sociology, Lakehead University, Thunder Bay,

ON P7B 5E1, Canada 
back to the ontological and epistemological challenges of social constructionism, particularly the strict form that she tends to adhere to. We went through many friendly rounds of debating, where I would try and argue that movements in parallel fields to social problems research (most centrally, non-modernist advances in social studies of science [Latour, 1993]) had essentially solved the problems of dualism in social constructionism, since the material world could also be seen as an actor in the co-construction of meaning. As such, I argued at the time (circa 2005), it was only now necessary for social problems research to benefit from these epistemic advances in order to find a symmetrical approach to social problems that did not privilege the "social" over the "material" aspects of problems in the world (see Del Rosso (2019) for a good argument in this line).

Not surprisingly, she disagreed! She was very good at defending the practical and ethical purposes of employing a constructionist approach faithfully as a way to avoid taking sides and getting caught up in political agendas, or making premature or unwarranted conclusions about the empirical world by falling into naïve objectivism. Most centrally, she thought, a strict constructionism avoids sliding back into "ontological gerrymandering" (Woolgar \& Pawluch, 1985) and maintains a consistent and relatively unbiased approach to analyzing claims. I still maintained my beliefs that constructionist dilemmas could be overcome, and would debate not only Dorothy, but also some of her students who made up the 'Canadian constructionist circle' at the time. All of these debates were a joy, and very enriching to my educational experiences while studying at McMaster. The sad part of this story is I never had the chance to get these thoughts and ideas that emerged from these debates and conversations onto paper. I have long been interested in transcending the epistemic problems of social constructionism, but did this in relation to symbolic interactionism (Puddephatt, 2009, 2013), science and technology studies (Puddephatt, 2005), or environmental sociology (Brewster $\&$ Puddephatt, 2016). Social problems issues were just never present enough on my research radar. With this special issue, I finally get the chance to elaborate my own approach to the ontological, epistemological, and practical issues of studying social problems claimsmaking with a constructionist lens.

The organization of this essay is as follows. First, I will recall Woolgar and Pawluch's (1985) original argument about ontological gerrymandering in an effort to salvage its intended purpose, which can often get lost in the telephone game of academic debate. I will then consider, as briefly as possible, the wellworn debates about strict vs contextual constructionism that ensued from here, following these to the present period. Second, I draw on the philosophy of George Herbert Mead to question the ontological and epistemological divides often taken for granted by social constructionists, leading to confusions over what ought to be treated as putative. Third, I briefly consider the charges of political irrelevance in regard to strict constructionism, especially in the context of calls for public sociology, the challenges posed by environmental sociology, and the fraught "postTruth" political landscape we are caught up in today (Adorjan, 2019; Pawluch, 2019). My overall hope is that social pragmatism might provide an alternative ontological and epistemological perspective for constructionist scholars to consider. Embracing G.H. Mead's wider ontological position and system of sociality 
may help to advance the practical and political goals of constructionist scholars in the present period.

\section{The Birth and Evolution of the Ontological Gerrymandering Problematic}

Woolgar and Pawluch's (1985) argument about "ontological gerrymandering" could well be one of the most discussed articles of all time in the hallways of the McMaster sociology department (not to mention its impact in the wider field of social problems). The authors use an "ethnography of argument" (p 214) approach to explore the argumentative logic of constructionist studies of social problems. This logic reveals deeper, implicit, ontological tactics that are often employed in studies of the claimsmaking activity with respect to social problems. Specifically, they observe that constructionists often rely on a particular repertoire of argument. This is usually in trying to convince the reader that social problem definitions could well be construed another way, and do not follow purely from objective conditions. ${ }^{1}$ In order to accomplish this, constructionists would have to make the case that either the objective conditions had not changed (e.g., the nature of marijuana, the existence of child abuse), or that the actual social trends (e.g., automobile crashes, teenage drinking) do not match the current definitions of such problems as being increasingly problematic. Moreover, this accomplishment rests on the constructionist becoming, for a moment of analytic convenience, an objectivist, making claims about the un-changing character of marijuana, or the decreasing rates of car accidents, for example. This leads to a tension between the "realist" ontology about background conditions, and the "constitutive" ontology of claimsmaking being the sole source of our understandings of social problems. This "selective relativism" is what amounts to "ontological gerrymandering," and might be a practical logic that is implemented to grant a different ontological status to social problems at different points in an argument, so as to garner maximum analytic effect.

The stated purposes of Woolgar and Pawluch's argument was threefold: first, a description of what social constructionists seem to be doing to build compelling arguments; second, a consideration of the ontological inconsistencies of this practice; and third, the possibility that any effort to present arguments about the social world at all might have to manage such ontological inconsistencies as a practical necessity. Most critics of the argument latched on to the second point of the critique, and tried to find ways to manage the contradiction of establishing objective conditions at the same time [as] locating social problems in social constructions. ${ }^{2}$ Andrew Abbott (2001) thinks Woolgar and Pawluch's critique is emblematic of his theory of fractionation, a tactic where theorists create space by taking the most extreme position possible in the space of possibilities. "Fractionation is thus

\footnotetext{
${ }^{1}$ It is a type of logic very similar to that found in the constructionist sociology of science, of which Steve Woolgar would have had a lot of experience (Latour and Woolgar 1979).

2 See for example Pfohl (1985), Schneider (1985), Hazelrigg (1985), Rafter (1992) and Troyer (1992).
} 
driven partly by intellectual virtues and partly by a kind of self-righteousness that becomes a vice" ( $p$ 86). In other words, by finding new space on the constructionist side of constructionists themselves, they enable relative critique and innovation, while also not having to compromise with objectivist problematics. There is probably something to this argument. And certainly, objectivism and constructionism has been in a fractally based war of expansion and re-appropriation of ideas since the early Greeks.

Contrary to Abbott (2001), I think that the ontological critique provided by Woolgar and Pawluch (1985) illuminated the constructionist/objectivist problematic in a rather new way, resulting in many theoretical and methodological defences over the years and forcing reflection and innovation in the field (see Ibarra \& Adorjan, 2018, for a review). For example, Joel Best (1993) argued that a "strict" constructionism as proposed by Spector and Kinsuse (1977) is probably not possible, since some objective leaps of faith have to be assumed eventually, no matter what methodology is employed. Further, Best argued that relying on some objective conditions is necessary to enable compelling arguments and make a stronger case, for example, not just about what claims are made but why they are, and even in some cases where they depart markedly from empirical reality. It is perhaps ironic that this agrees precisely with Woolgar and Pawluch's (1985) first point of their original critique, that ontological gerrymandering, no matter the ontological problems it invites, may just be necessary to building a compelling constructionist argument.

Best's contextual constructionism is not really an ontological or epistemological answer to Woolgar and Pawluch's philosophical dilemma, but more a practical decision about how to do research and build arguments most effectively without worrying so much about the philosophical contradictions (see also Spector, 2019). The title of Best's (1993) oft-cited chapter, "But Seriously, Folks," says it all; perfect philosophical consistency is not possible - we all know there is a real world out there - so let's just get on with things. Crawley (2019) more recently has argued that we need not reach for one unified epistemology, but might benefit from treating them as tools and moving between them creatively as cases require. We can also use competing epistemologies as useful reference points of mutual critique, with an eye to improving things. This is perhaps a more philosophically enlightened effort to mend the discrepancies in shifting back and forth between objectivist and subjectivist positions, and get on with the practicalities of doing good constructionist research. Reflexively, I might offer this essay both as an alternate epistemology that strives for internal consistency, but if not, it might at least offer a reference point to better critically appraise the foundations of strict constructionism. Dorothy Pawluch (2019) has herself reflected on such "contextual compromises" in defending her own brand of "stricter" (if not perfectly strict) constructionism for the strategic payoffs it can offer research.

Lawrence Nichols (2003) points out that claims cannot be considered contextfree, even in the realm of language and representations alone. Words or phrases, for example, might be taken "out of context" if the full discursive situation is not 
well understood, and such phrases often contain many references to context. ${ }^{3}$ Once we start to account for the discursive context of claims made by one actor, it is not a great leap to consider how these fit into much wider contexts of claimsmaking around an issue across wider society. Contexts must, in other words, first be adequately established in order to properly analyze the discourse surrounding social problems. Building on the work of Mikhail Bakhtin, Nichols suggests a "dialogical approach" to analyzing claims instead of the more popular tendency toward analyzing claims as "monologically produced" (p 96). That is, claimsmakers are usually involved in claims and counter-claims as they react to one another, in a complex and overlapping manner, particularly when the claims are considered controversial or involve quite heterogeneous groups. Mapping out the dialogical discourse of claimsmaking from many actors and collectives across many social worlds may be one way to establish context and enable a multi-vocal (and more fulsome) analysis of the activities in question. Later, Nichols (2015) considered context not just as a pregiven entity, but also the product of actors' "context work" and "context gaming" as they strive to enable a landscape that better facilitates their interests. Yes, contexts are products of construction but they also provide conditions of possibility.

While Nichols invites a wider set of actors to be included across the social mosaics whereby claims are made (see also Christensen, 2019), Del Rosso (2019) suggests that such mosaics must be cast wider still. Building on the actor-network theory of Bruno Latour (1993, 2005), he argues that claims are not made in linguistic vacuums, but through chains of associations between human and non-human actors. It is the wider collective of nature, technologies, instruments, knowledges, and people, and how they interact across concrete sites of activity that allows for constructions to be possible in the first place. For Del Rosso, a constituted ontology need not be an exclusively "social constructionist" ontology that leaves out the important role of the material world and nonhuman actors in how claims and forms of knowledge are put together.

By considering the process of constructionism as being made up of "chains" (networks) of associations, analysts do not strive for absolutist realism, to try and prove claims to be "right" or "wrong." Claims and products of knowledge are always continually evolving as networks of association are re-arranged, displaced, or expanded, for example. The history of science shows us that such artful productions of humannonhuman arrangements have been cast aside once they enter into "crisis" and give way to new paradigms (Kuhn, 1962). ${ }^{4}$ Yet by taking the material production of

\footnotetext{
${ }^{3}$ Nissenbaum (2010), for example, argues that appropriate expectations about privacy cannot be presumed without consideration of social context (roles of speakers, subject matter, audiences, norms of the communicative culture, etc.).

${ }^{4}$ Farley and Geison (1974) discuss the experiments and counter-experiments between Pouchet and Pasteur in a battle over the reality of spontaneous generation in the late nineteenth century. Some of the experiments showed growth in the test tubes that might support the thesis of spontaneous generation. Pasteur later convinced the scientific majority that the growth exhibited in the test tubes were the result of contamination, but for at least some of the debate, "empirical reality" was on the side of Pouchet. Latour (1993) would point out that it is not that material reality always leads us to the truth, just that it leads us, as a kind of claims-maker of its own, without any obvious interests in choosing sides.
} 
claims seriously, we can discern differences between claims that are carefully constructed (calibrated) through many reliable chains of human-nonhuman networks, and those which seem to be produced more from thin air (Del Rosso, 2019). Thus, for example, understanding how claims of election integrity are provided by US electoral officials would require an in-depth investigation of the many links between proof of citizenship and district, ballots, digital scanners, volunteers, computer systems, accounting software, and procedures to check and recount the votes across multiple districts. Claims of election fraud would have much shorter chains if little evidence can be found at these levels, and hence, would weaken their likelihood.

Del Rosso (2019) is correct that Latour avoids the choice between social constructionism and naïve realism by allowing non-humans into the mix of relevant social actors who participate in the constitution of social problems. Using this framework solves many of the problems identified by Woolgar and Pawluch (1985), for example, in their critique of Pfhol's (1977) analysis of the "discovery" of child abuse. Pfohl tries to make the argument that "child beating" had not changed over a great deal of time, but it was only by the 1950s that "child abuse" was constructed to clinically problematize it. While physicians were too close to parents to get involved in domestic and legal issues like this, other emerging groups were not. Pediatric radiologists, pediatricians, and psychiatrists did not have close ties to families and had the freedom (and the institutional interests) to shine a spotlight on child abuse. Pfohl argues that since their research was "medically-based" and not "legally based," they were empowered to make progress by avoiding the legal barriers that would otherwise prevent them from speaking out about the problem. Yet an actor-network theorist would submit another very important point that Pfohl entirely misses. Pediatric radiologists, with the use of X-rays, can show the long-term physical harms of beating, while psychiatrists and pediatricians could provide evidence of the longterm psychological harms from their clinical case studies. It is the piecing together of case studies and images through these various human-nonhuman associations, where the effects of child beating were revealed for the first time, which gave rise to the label of child abuse. These are not merely different labels for the same unchanging phenomena, since the latter refers to the hidden, long term effects of child beating. Child beating is an act, child abuse refers also to the physical and emotional effects of the former.

A similar case could be made for Spector and Kitsuse's (1977) claim that marijuana did not change over time even though claims and policy surrounding it did. Latour (2005) would likely argue that marijuana actually did change over time, as it became a perceived public nuisance, a part of rebellious musical and political movements, and an element of medical research in ways that it was not in the past. Thus, our human/nonhuman chains of association with marijuana became quite different over time, and thus led to a different conception of, but also stabilized reality of, marijuana itself. These point to Mead's (1932) argument that the "meaning" of any given object does not lie in its objective properties alone, but emerges through its relation to other objects in systems of action (Puddephatt, 2009). Yet one might also make the case that once marijuana started to be grown hydroponically, and efforts were made to intensify the THC content, not to mention lacing it with other drugs, it actually became more potent bio-chemically, and hence, perhaps more worrying to 
policy makers and health authorities. In other words, the objective reality of marijuana did probably change over time.

But let us return back for a moment to Woolgar and Pawluch's (1985) raison d'etre for their compelling essay. They ask us to "search for forms of argument that go beyond the current impasse between proponents of objectivism and relativism" (p 224). In other words, "What would an argument free from ontological gerrymandering look like?" ( $\mathrm{p} 244$ ). It is precisely this question I focus on here, and argue that a social pragmatist position does allow for constructionist research within a consistent framework that avoids ontological gerrymandering. It has been conceded that an entirely strict constructionism is not practically possible (Pawluch, 2019), while contextual constructionism is split between competing ontological and epistemological stances. Crawley (2019) argues for the use of multi-epistemology studies as useful references for criticism and advancement rather than finding one coherent system once and for all. In contrast, actor-network theory does seem to unite around epistemological consistency, by dealing with all claims as chains of association in a wider socio-material network of activity (Del Rosso, 2019). It must be said that actor-networktheory is not without its problems, however, as it tends to de-center human agency, forbids using macro-structural forces as explanations, and has a method of analysis that is very difficult to pin down, even by its own author (Latour, 2005). ${ }^{5}$

We can see there have been a range of attempts to bring objectivity back into subjective accounts in constructionist theorizing. As Abbott (2001) might argue, such attempts are the natural result of fractionation, in that by pushing too far in one direction, social constructionists now have a great deal of intellectual space to make up for (e.g., materialism, the need for objectivity). ${ }^{6}$ At any rate, new attempts are often made to "fix" the idealist fractionation of social constructionism, conveniently forgetting the older systems that it branched off from. Instead of trying to add an even newer materialist spin onto strict constructionism, then, I instead return to an older branch of knowledge it stemmed from, which is the pragmatism of George Herbert Mead. ${ }^{7}$ It is worth remembering that Mead was the teacher and inspiration to Herbert Blumer, himself the founder of symbolic interactionism. And Blumer, in turn, was a big inspiration for the early constructionist approach to conceive of social problems as "collective behaviour" (Blumer, 1971; Ibarra \& Adorjan, 2018: 280). Further, not only is Mead an important forefather of constructionist thought, but he is also exemplary for his efforts to transcend philosophical dualisms that are at the heart of constructionist dilemmas. He presents a sociology of knowledge that is "constitutive," "processual," and "relational" (hence avoiding naïve realism) without falling into the traps of an idealist subjectivism, which he took great pains to

\footnotetext{
5 For a humorous illustration of these difficulties, see the interlude that involves a dialogue between Latour and a frustrated graduate student about [the] confusions of utilizing actor-network theory (Latour 2005: 141-156).

6 Some of the recent calls from Dello Buono (2013, 2015), for example, might be indicative of this effort to find space to reground material conditions that might allow for critique.

7 I have argued elsewhere that Mead's thought contained much of what was later "discovered" by Latour in regards to our constitutive and mutually impactful social relationships to nature and the nonhuman world (Puddephatt 2005).
} 
avoid (Puddephatt, 2013). His social pragmatist theory thus makes for a useful vehicle to navigate constructionist dilemmas and seek out a more consistent ontological and epistemological framework.

\section{What is Putative? Moving From the Ontological to the Epistemological and Back Again}

Woolgar and Pawluch (1985) wrote about "ontological" gerrymandering, which refers to the basic assumptions we are prepared to make about the real world. Woolgar and Pawluch seem willing to accept the reality of the social universe, where other subjectivities and languages exist, and people try to make claims about reality. Thus, they go further in their ontological assumptions than Descartes' starting point of cogito ergo sum. Instead of being agnostic about the possibility that an evil demon is playing with our senses, and fooling us into thinking there is a society, they appear to believe there actually is a society with other people inhabiting it. One could argue that there is really no reason to stop there. If we are to move beyond accepting the reality of our own consciousness, to accepting the existence of other minds and selves who share ideas through language, then why not also assume we can know actual physical spaces, places, and things that mediate and often structure social life? Indeed, Latour (1992) might ask, "where are the missing masses" in such an account? It is unclear how knowledge of material reality cannot be assumed, but knowledge of a social world can.

Further, the ontological rules (what we assume to be true) tend to bleed into epistemological rules (how we can figure out what is true). Thus, I could be ontologically agnostic about the existence of my desk even though I am staring at it. But from an epistemological perspective, I tell myself, if I hit the putative desk with a hammer and smash through it, it might be a good indication that it was actually there after all. My epistemological approach leads to a kind of hypothetico-deductive experiment, with the associated methodology of trying to demolish my desk with a hammer. Should the desk break, it would better establish its "thereness," thus impacting my present ontological assumptions about its existence. While also sneezing on the sawdust, I would now have even more reason, perhaps, to believe it is there. I admit it is still possible that my perception of the desk breaking, and me sneezing, are also illusions, so that smashing it ultimately proved nothing about its putative reality. ${ }^{8}$ Still, if one is to move from a position of doubt to a position of reasonable certainty (in other words, shifting one's ontological commitment), one must ask these sorts of epistemological questions to get there. ${ }^{9}$

\footnotetext{
${ }^{8}$ As a humorous aside, I have since realized that if I was capable of hitting a desk with such force that it would result in a cloud of sawdust, I would more likely be dreaming.

9 Melvin Pollner $(1978,1987)$ might consider this type of internal conversation and experiment as "objectivating discourse," whereby I seek to reify my desk and sense of ontological security. Mead (1938) might counter that the material world, in turn, provides "subjectivating contexts" whereby consciousness, meaning, and perspectives are generated.
} 
The same is true when we attempt to know the social world, the so-called "subjective realm," and if we like, and the realm of "claimsmaking." This is where Mead's philosophy becomes very helpful. First, recall that Mead's (1934) theory of the self involves the relation between the "I" (self as subject) and the "Me" (self as object). Note that for Mead, one can never be aware of the self as an active "I," since this exists only in the knife-edge present, passing out of consciousness before we can grasp it. ${ }^{10}$ One can only gain access to the "I" once it has fallen into the past and become transformed into a "Me." Thus, the only way to know one's own subjectivity, let alone anyone else's, is to first objectify it, so as to fix it in place and reflect upon it. Mead did indeed argue that we are able to deliberately construct our physical environments in various ways, and we perceive them through our own subjective frames of meaning. Yet our subjectivities are not given, since like all products of nature, they emerge from our immersion in the physical and social world. He called this the "objective reality of perspectives" (Mead, 1932: 171-182). Put simply, subjectivities cannot develop independently from the material environments in which they are formed. Further, once formed, they are every bit as "real" as any other "slab of reality" (McKinney, 1955). There is a mutualism that exists between our development within, and our ability to act back on and change, our physical environments (Brewster \& Puddephatt, 2016).

Striving to know ourselves is one thing; knowing others is even more difficult. How can we solve the problem of "other minds" (McVeigh, 2016)? How do we gain access to the magical world of human consciousness beyond our own experience of it? This forms the foundational basis of the problem of artificial intelligence - we can create excellent simulations of consciousness with machines, but we cannot actually create consciousness itself in machines, because we cannot gain direct access to other minds (Wolf, 1991). Ontologically, then, constructionists may take the position that they do not want to make pre-formed assumptions about someone's viewpoint, or the forms of their claims, before they have a chance to inquire about them. As such, epistemologically, they set out a set of methods (perhaps textual analysis, or interviews) to try and find out. Proceeding with methods like this then gives them more ontological certainty about the substance and form of the claims they are trying to describe, than before they started the inquiry. Yet this means that they must try and assess these subjectivities through the use of objective indicators. Is it an utterance from an interviewee, who emits sound waves that is passed through a digital recorder and then recalled through one's auditory faculties during transcription? Is it the visual sense of text that interacts with the structure of the researchers' eye, and provides the objective means to assess claimsmakers' opinions and rhetorical style? Mead would ask, how is striving to capture subjective views through objective indicators any different from striving to capture objective conditions through objective indicators?

For Mead (1938), these epistemological processes are exactly parallel. There is not a social world on one level, and then an outside world of things on another. This

\footnotetext{
${ }^{10}$ It is possible that the practice of Buddhist meditation might be a counterfactual example to challenge Mead's assumptions about our ability to experience subjectivity in real time (Adorjan and Kelly 2008).
} 
dualist notion of a split world of things and representations forgets how mutually constitutive both are through time. The physical universe is at root a social world of complex relationships of cause and effect between mostly nonhuman but some human entities, which shapes our perceptions, and generates emergent experiences that shape meaning (Mead, 1932). The fact that the world is made up of a number of overlapping systems that affect each other all the time in unseen ways is the very basis of his core principle of sociality, on which his theory of society ultimately rests ( $p$ 49). We develop social relations with things, and come to know them, perhaps imperfectly, through our interpretation of their outward behaviour. Scientific experiments promote ever more intricate social dialogues with things so as to strive to understand them (Mead, 1938: 215-268; Puddephatt, 2008). ${ }^{11}$ We also develop social relations with people, of course, but still can only come to know them, again imperfectly, through signs from their outward behavior to make inferences about who they are. Police interrogations, or cross-examinations on a witness stand, are much like scientific experiments, in a way, by placing people in unnatural environments, and prodding them to react, to try and uncover the truth about them.

This then begs the question: Why do social constructionists always call conditions "putative" but not the makeup of the claims themselves as "putative"? What epistemological reasons are there to have faith in getting the content of the claims correct, but not the objective conditions? From a purely epistemological point of view, why would a transcribed interview provide better evidence of the content of an actor's claim than a statistical analysis would provide evidence for the reality of a youth crime rate? Both the essence of the claims and essence of the conditions would have to be inferred through objective indicators. Since this is the case, why privilege the analysis of subjectivities as unproblematic (in contrast, and to our credit, these are very hard to study!) while deeming knowledge about the objective world to be off limits? Surely the content of claims can be confidently captured in some cases, but at other times misunderstood if people mis-speak, are taken out of context, or are simply mis-interpreted. Similarly, there are times when one is relatively certain of what is going on in the objective world (e.g., I now have my feet up on my office desk, and feel confident it is there), while at other times, one is much less certain (walking through a "house of horror" designed to trick the senses, for example).

Mead (1932) is useful in overcoming this dualist prejudice, as he saw no neat dividing line between natural and social processes: both are contingent, relational and processual, part of the wider system of sociality that leads to continuity but also emergent surprises (Chang, 2004; Puddephatt, 2013). He recognized we can never wholly know anything once and for all, as our sense of reality is always dependent on inferences from direct experiences through action, with both things and people. We can only develop best guesses about the constitution of the world and the people who inhabit it, and such best-guesses are only possible by entering into

\footnotetext{
${ }^{11}$ I was listening to a theoretical physicist on the radio the other day who was grappling with the problem of dark matter. She argued that people often forget that science is not about what we know, but about what we don't know.
} 
more intensive relations with the other (whether human or nonhuman), and judging the outcome of ongoing actions with an eye to practical effects (Smith, 1963). One might argue that the method of ethnography and intensive interviewing allows for intersubjective connections that lend a shared collective consciousness. Yet such social connections, and the sense of shared understanding they generate, still cannot escape the philosophical problem of "psychologism," which is that all knowledge claims about the empirical social world must stem from perceptive experience (Popper, 1959). Intersubjective experience may well make up reasonable grounds to establish actors' actual claims, but this has no special epistemological privilege over particular experimental or survey methods being reasonable grounds to establish certain natural or social facts.

One can see these issues emerge in a revisit to Michael Adorjan, Antony Christensen, Benjamin Kelly, and Dorothy Pawluch's (2012) excellent article "Stockholm Syndrome as Vernacular Resource." Why did Stockholm syndrome, which began as a term for hostages irrationally bonding with and defending their captors, morph into a discursive resource for understanding topics such as battered women, victims of child abuse, prostitutes, cult members, and pets? They help explain the mechanisms through the words of Yvonne Ridley, who was held captive by the Taliban and then later converted to Islam. Ridley writes:

a Western woman has rejected what they see as Western values to embrace Islam. Because they can't understand it, they fear it. And because they fear it, they have to attack it. The easiest thing they can come up with is Stockholm Syndrome (Csillag, 2007, as cited in Adorjan et al., 2012, p. 468).

Building on this and other cases, Adorjan et al. (2012) argue that Stockholm syndrome serves as a vernacular resource to neutralize, pre-empt, or remove arguments claimsmakers disagree with. If one cannot fathom a woman wanting to stay with her abusive husband, for example, it is easier to cast her as irrational and under the spell of Stockholm syndrome than to actually hear out her side of it. This is especially so if that side challenges deep cultural beliefs of "what we all know" as part of our common stock of knowledge (Pollner, 1987) about women being trapped in abusive relationships. It is a fascinating article and a great case study of domain expansion and the rhetorical strategies that may be at work in the invocation of the term.

What strikes me, however, and perhaps bolstering Woolgar and Pawluch's (1985) original argument about the rhetorical style of constructionism, is that the best parts of their argument can be found in their frequent flights into objectivity claims. For example, they believe that the Stockholm syndrome term first originated in Sweden in 1974 as reported (objective claim) but remain agnostic as to whether the concept itself is accurate and valid (constructionist). They believe they can track mentions of the term and establish the fact that Stockholm syndrome became popularized and started to spread, first through the psychiatric and criminological literature, and then out to other areas far removed from its initial application (objective claim). They do this with the use of searchable online databases such as Factiva (does the name say it all?) and LexisNexis, providing quantitative charts to prove their claims about said domain expansion (objective claim). In de-constructing the Stockholm syndrome claim, and looking closely at the case of Yvonne Ridley, they again impose 
an overlying claim that there is a wider, perhaps unconscious function being served that the claimsmakers may not be fully aware of. They notice a common pattern of how the concept is used across many different sites as a vernacular resource to neutralize or eliminate antagonistic ideological views (the key thesis of the paper, and a great one, but itself also an objective claim). Thus, the genius of that article is in its reaching beyond the limits of merely capturing others' subjective claims, and getting to the more central task of making objective claims about a hidden dynamic at work in the broader arena of discourse.

Let us now return to the question of what we ought to consider putative. The answer lies not in what are classified as subjective claims on the one hand, or objective facts on the other. With the help of Mead, we have already established that we might have good reason to be certain or uncertain of either subjective and objective realities equally. Instead, our decision to treat things as putative might be more usefully thought of as how controversial certain ideas are, and whether there is energy being used to fuel the disagreement. Harry Collins and Trevor Pinch (1993) for example, pioneered "controversy studies" in science, in which they would purposely select cases where scientists disagreed about particular truth claims, organizing into rival camps. They had to be agnostic about the reality of either side of the truth claims, since the science itself had not resolved itself, and as such they would have no claim to the expertise needed to figure out which side was right. Similarly, Harry Collins $(1985,2004)$ spent his career studying the scientific controversy surrounding gravity-wave detection. He tracked the experiments by Joseph Weber in the 1970s, who claimed to have detected gravity waves, and counter-experiments by his rivals who argued that it was theoretically impossible to detect them and that his readings amounted to no more than noise. ${ }^{12}$ According to Collins, the critics won the dispute not necessarily due to the weight of evidence, or scientific agreement around a "crucial experiment," but because Weber's detractors were successful in harming his reputation and defeating his credibility. The funding stopped, and the search for gravitational waves seemed to be over with. Critics of the cultural studies of science might argue that Weber did not lose in the scientific controversy due to the social factors privileged by Collins, but because he was simply wrong about detecting the waves. Yet in 2016, lo and behold, the scientists behind the laser inferometer gravitational wave detector (LIGO) announced to the world they had successfully detected gravity waves, which would revolutionize physics, earning them the Nobel prize in the following year (Choi, 2017). We simply cannot know how controversial knowledge will be settled while it is still in the process of contestation.

Similar tactics of ontological agnosticism abound in environmental sociology, but again not according to subjective and objective boundaries. Burningham and Cooper (1999) observe that most constructionist environmental studies employ a "soft" or "weak" constructionism in which only certain facts are left open to speculation. This is a practical necessity in environmental sociology since theorists feel it is important to support the efforts of environmentalism and accept the reality of

\footnotetext{
12 There is far more to this story, of course, but the details are beyond the scope of this discussion and not so important for my central point.
} 
scientific consensus about things like climate change, while still analyzing aspects of the issues that are more controversial. For example, Jerry Williams (2017) used a phenomenological framework to analyze the debate about the possible connection between oil-fracking and earthquakes in Texas. He points out that everyone agrees there is increased oil-fracking in Texas. Everyone also agrees there have been an uptick in earthquakes in Texas that correspond to the same time period. However, where there is large-scale disagreement is whether the two patterns are causally connected, that is, if the oil-fracking is responsible for the earthquakes. Hence, this is where the analysis is focused, and where a phenomenological form of constructionism comes in so handy to understand people's divergent views. He finds the major fault lines of religious and economic vs. scientific and environmental worldviews are largely responsible for the differential framing and perception of the issue by everyday people. What is important for our purposes is he has to remain agnostic about whether or not the causal connection is real, since science has not had enough time to prove the connection is not just coincidence; in other words, there are grounds to treat the causal association putatively. Yet this does not require him to also be agnostic about the existence of Texas, the increased practice of oil-fracking, and the increased rate of earthquakes. As another example, constructionist environmental scholars might recognize the broad agreement by the International Panel on Climate Change (IPCC) that climate change exists and is humanly caused, yet might find disagreements within about how much this so, which specific climate models are most accurate, what the bounds of possibility are, and how we can best deal with the problem (Giddens, 2011). In other words, it is in the sites of contestation, not in agreement, where an ontological agnosticism makes sense, where domains can be defined putatively for good reason, and where constructionist analysis can be so insightful.

This may be why the Adorjan et al. (2012) article is so compelling. Perhaps without realizing it, in practice they tend to follow the epistemology and rules for establishing ontological agnosticism advocated by Mead's social pragmatism, rather than that of strict constructionism. They establish certain facts as uncontroversial (Stockholm syndrome as a term first originated from a hostage situation, it spread through the psychiatric and criminology literature, and underwent domain expansion). They remain agnostic about what is controversial and beyond their expertise to determine (whether "Stockholm syndrome" is actually a psychological mechanism and if it really works as some say it does, due to controversies in the literature). Then, to craft a compelling thesis, they submit their own somewhat controversial objective claim (Stockholm syndrome works as a vernacular tool of neutralization) even though there is good reason to think that some will find this claim unfair and disagree with it.

The power of their argument, hence, is in taking a leap of faith and making a very interesting objective claim without the benefit of total certainty, but as part of a strong case that is rooted in good evidence. Bruno Latour (1993) may come in handy here again, in his discussion of "variable ontologies," where he establishes that both social and material reality can be said to be more or less "stabilized" (p 86) at different times. As scientific facts, or social claims, become commonplace and are distributed and widely accepted and used, they tend to achieve a higher degree of stabilization, and no-one is doing the work to question them. Sometimes, facts that 
were once stabilized get re-opened, as when a new scientific discovery challenges received wisdom, or a new discursive claim challenges those from the past. Indeed, it is always in these areas of open-endedness and speculation where ontological agnosticism is both warranted and highly interesting as a strategy for social analysis. It is not about the proclaimed subjectivity or objectivity of the object in question, but the degree of stabilization in place, that ought to determine whether and how to treat conditions and/or claims as putative. In Pawluch's (2019) terms, destabilized aspects of situations may call for the "stricter" style of agnosticism, while stable aspects may do better with sharing assumptions about reality with vast majority. Or, in Pollner's terms, such stabilized situations provide very good grounds for constructionist researchers to make sure not to "argue with the members" (Gubrium \& Holstein, 2012).

\section{Constructionist Politics?}

Various arguments have been made over the years for the political consequences of taking a strong constructionist position due to the issue of relativism. This has been hotly debated in the field of environmental sociology. If there is no way to adjudicate once and for all between the claims of climate change deniers and advocates, for example, realist critics argue that it is difficult to engage in political activism and get on the right side of the debate. For proponents of the "new ecological paradigm," relativist views on the problems of climate change and other environmental threats simply will not do (e.g. Catton \& Dunlap, 1978; Murphy, 1995). We must instead choose ontological and epistemological strategies that allow us to build on the best scientific evidence available in order to join the good fight. Adorjan (2013) finds a similar set of worries emerging with the rise of public sociology, as efforts to stay "on the side" (Gusfield, 1984) and agnostic to claimsmaking positions are rejected in most quarters. Pawluch (2019) observes that these worries are only heightened with the advent of the "post-truth" world we inhabit where polarization, and paranoid conspiracy theories are given so much credence in a mass-media saturated world of social media. The perception is that truth is slipping away, not only in the halls of academia, but in wider society itself. This only strengthens critical theorists' resolve to obtain realist epistemologies that allow for critiques by re-grounding reality in this post-truth moment in time (Adorjan, 2019).

It is this spirit that led Dello Buono (2015) to argue in his presidential address to the Society for the Study of Social Problems (SSSP) for a move beyond constructionism. He argued that the agnostic analytic strategies of social constructionism are a-political and idealist, and have no capacity to weigh in on the structural conditions of modern capitalism and the forces of neoliberalism. Rather than remaining in a "docile and politically useless attitude of detached reflexivity" (Dello Buono, 2013: 795), we must develop a critical attitude to how social problems are shaped by powerful historical and material forces so that we can strive to bring about positive change. From a pragmatist perspective, the trouble with Dello Buono's call to arms is not so much the effort to study real material conditions, but the dogmatic political assumptions embedded in revolutionary 
neo-Marxism, rendering any other form of reformist or status-quo politics illegitimate by definition. By bracketing off the majority of the contemporary political spectrum as a form of false consciousness, Dello Buono does not have to listen, learn from, or engage with it. Rather than an agonistic politics of honest engagement with our adversaries, we have an antagonistic politics that only wins by dismissing mainstream opponents by definition, effectively taking them out of play beforehand (Selg, 2013).

Pawluch (2019) avoids dogmatic and arrogant assumptions connected to a onesided revolutionary politics, arguing instead that perhaps the greatest virtue of social constructionist research is precisely not to get trapped in the political agendas one studies, but to remain disciplined, and strive to understand them analytically (see also Prus, 2007). Christensen (2013) did exactly this in his constructionist analysis of the broader movement of public sociology itself. Adorjan (2013) made the case that constructionism has great promise for public sociology because of its discipline to stay "on the side," so as to establish the logic of all relevant arguments at hand. This way, people can get a better sense of the wider maps of discourse surrounding an issue and, perhaps, begin to see things from the other perspective. Burningham and Cooper (1999) argue that agnosticism with regard to heated environmental issues may be the preferable position ethically, especially if the scientific-political debates that rage on are unsettled. Taking a firm stance on one side of the debate over genetically modified foods, for example, would be premature and one could well end up on the wrong side of what gets settled over enough time. It probably does not need to be said that being "agnostic" about reality does not mean denying it, or any particular form of it. Still, this is usually not enough to satisfy realist critics who want to push hard for social change and make firm assertions about the reality of social (or ecological) conditions as a way to forward their particular political agendas (Murphy, 1995; Dello Buono, 2015).

Being careful about assumptions about reality of the social and material world, while not retreating from them entirely, is again where the philosophy of G.H. Mead (1932, 1938) might be useful, since he does not allow a neat dividing line between subjective and objective forms of knowledge, privileging neither epistemologically. Knowledge of the subjective and objective worlds are equally contingent, relational, and subject to our representations of them. In other words, the social and material worlds are equally ontologically and epistemologically problematic. Of course, this does not mean we give up on trying to produce accounts of them. A pragmatist position is one that makes the most accurate assertions one can about the nature of the physical, social, or subjective world, and revise as disconfirming evidence is inevitably encountered. Knowledge is not adjudicated through some ultimate ontological boundary, but rather whether or not the consequences of applying said knowledge leads to expected or beneficial results. This is a position Mead shares with the other American pragmatists, such as Charles S. Peirce, William James, and John Dewey (Prus \& Puddephatt, 2009; Smith, 1963).

For Mead (1923), this doctrine becomes especially useful in politics, since it allows a scientific logic to be used to weigh natural facts along with social values in the effort to find rational solutions to public issues. Mead (1923: 236) writes: 
what scientific method does require, if is to be consistently used, is that all the conflicting ends, the institutions and their hitherto inviolable values, be brought together and so restated and reconstructed that intelligent conduct may be possible, with reference to all of them.

Much like Habermas (1987) would later argue, social conflicts and struggles for equity might be found through a doubling down on rationality, as issues can be debated and resolved in ideal speech communities in the life-world. We need not accept Mead's nor Habermas's naïve faith in the democratic possibility of fully rational debates about social problems as undistorted by powerful interests. Yet an ontological-epistemological system that allows human values, frames, and claims to be weighed alongside of material conditions and scientific facts is fair game in Mead's system of thought. We all have our own beliefs and values, and we cannot be conceived of as a free-floating intelligentsia, as Mannheim (1929) may have implied. Yet to the extent we strive to remain analytical and detached, we are far less entwined with the social interests at stake than those fighting these issues out in public spaces. Our comparative neutrality to other social institutions is at the very least a strong relative advantage in striving for the balanced analysis of competing claims, which makes social constructionist approaches quite viable and useful. Using Habermas (1987) again, perhaps as scholars we can create our own subjective ideal speech community within our self-dialogues through scholarly writings, even if we cannot expect such relatively free discourse among our politicians or those with powerful interests. This means that constructionists can build potential political solutions into their writings, by generating a kind of meta-analysis of conditions, frames of meanings, values, and the interests of competing groups to seek compromise.

Following Mead's wider philosophy of sociality enables us to make claims about how people make claims, but also make claims about the apparent conditions on the ground, without being philosophically contradictory. This enables us to be able to stay attuned to the sway of corporations, the state, and news organizations in the shaping public opinion (Altheide, 2002; Musolf, 1992). We might also pay attention not only to the contexts in which claims are made, but also how these contexts themselves are constructed in more or less favorable ways (Nichols, 2015). We may need to examine how certain structural inequalities provide the conditions for discourse to emerge and take shape. For example, the pharmaceutical industry has recently warned that a temporary lifting of patent protections for the covid-19 vaccines (allowing for the production of generic vaccines globally) would be dangerous for the production process and for health and safety. It is clear that this position is at least partially influenced by this industry hoping to maintain the legal structures that favour them monopolizing the market and maximizing their financial outlook. Mead's pragmatist position allows us to consider the financial and legal contexts within which such claims take shape, while still recognizing that new distributions of power can emerge unexpectedly from these heterogeneous discourses (Athens, 2015; Chang, 2004). Who is to say how these discourses will play out, and what the results will mean for upstart pharmaceutical companies in developing regions? In this way, we could build on Mead's more complex ontology of the social to explore further how social constructs are shaped within specific structural conditions, and 
do not appear out of a vacuum (Adorjan, 2019; Nichols, 2015). Mead's (1932) system of sociality allows for a detailed consideration of how conditions and situations are perceived and framed, but also, how perceptions and frames get formed within the play of material and social conditions. This is the big payoff of embracing his much wider system of sociality, which sees both subjects and objects as products of emergent processes through co-evolutionary activity in the world.

\section{Conclusion}

I write this essay as a celebration of Dorothy Pawluch's amazing career and her passionate and disciplined approach to addressing social problems. Her work and teachings have had a tremendous impact on so many and enabled a community of constructionist scholars across Canada to flourish. I have richly benefitted from knowing her and it is out of our playful debates where the material from this essay originated. Her resolve to encourage us to study political movements, but not get mired in them, is particularly welcome and important in the times we are facing (Pawluch, 2019). All too many professors are teaching students today that since we cannot eliminate our biases we should embrace them full force, at the expense of trying to see things neutrally, or at least from other points of view. Instead, the effort to stay disciplined analytically, and not get swept up in the latest social and political trends of the day is laudable. Ironically, staying disciplined and striving for value neutrality might actually provide us with better sociological analyses, leading to a more realistic understanding of the moral discourses surrounding us. As such, I applaud the effort for value neutrality and far prefer this to dogmatic political activism under the false auspices of scholarship, defending an artificial epistemic privilege through narcissistic or confessional forms of reflexivity (Bourdieu, 2004; Day, 2012; Lynch, 2000). Purposely abstaining from political opinions to re-center careful empirical work and social analysis is surely a good antidote to blatantly partisan theory and research. ${ }^{13}$

As for my own position, I am not sure if we can ever be value-neutral, but we can make greater efforts to see issues from others' points of view. Perhaps a balanced, polyvocal mapping of discourse is the closest we can get to a neutral position. For Mead (1923), it is out of this careful stock-taking of varying interests that we can begin to play with, and work out, potential political solutions. ${ }^{14}$ If one chooses to remain analytical, and not offer policy solutions or political resolutions, a pragmatist

\footnotetext{
${ }^{13}$ Lawrence Nichols makes an interesting distinction between what he calls "analytic," "critical," and "partisan" versions of constructionism. Analytic constructionism presents the variety of claims without taking sides on their truth or falsity. Critical constructionism tries to ascertain how and why claims either converge or diverge from reality. Partisan constructionism takes sides with one wing of the conflict, and sees them as factually and morally right, blending with standpoint epistemologies (personal communication). This is another useful way to think about the conceptual boundaries between strict, contextual, and more activist types of constructionist work, and their willingness to make certain kinds of epistemic or political claims.

14 It is worth noting that Mead was a very public intellectual in his time, and never drew a firm line between his pragmatist philosophy and political engagement, since the latter grew out of the former (Huebner 2014).
} 
framework provides a consistent philosophical foundation from which to do so. If one does want to go out on a limb and make a political conjecture, there is nothing stopping this since establishing facts and values have no absolute distinction epistemologically (Latour, 2005). Yet to do so, Mead (1923) would argue one would need to be extremely careful to include all relevant parties and strive to understand the issues from all relevant points of view. This is where the constructionist methodology of mapping claims across arenas of discourse allows for a more complete picture of political contestation, which, purposely or not, may provide the potential for mutual understanding and progress toward solutions or compromises (Adorjan, 2013).

Mead's (1929) ethical philosophy is relevant here as well; that is, the greater we expand our communities of inclusion, the greater our ethical capacity becomes. Thus in social problems work, the more we listen to and engage those whom we disagree with (yes, even those on the right wing!) the more our ethics will expand as we come to take the roles of an expanding array of others. Building on this logic, Brewster and Puddephatt (2016) argued that by expanding our social groups even further, outside of human communities and into the nonhuman world of nature, our ethics might expand more still. Developing "eco-selves" that take nature into account as part of the generalized other help people to think more about their everyday habits and the treatment of the natural world. Using the same logic, perhaps Mead's (1932) philosophy of sociality, which embraces both people and things in wider nets of collective action, will allow for an ethical expansion of social problems work as well. Scholars can reach out beyond discursive communities alone, and begin to embrace, make claims about, and learn from, various relevant aspects of the actual social world itself, not just what the claimsmakers allow them to see of it. ${ }^{15}$ By recognizing the need for leaps of faith in trying to capture the reality of claims, constructionist scholars might also be liberated to make their own claims about the current state of social conditions, and even to search for practical solutions.

Acknowledgements I would like to thank Michael Adorjan for inviting me to contribute to this special issue, and for his fine editorial suggestions. I would also like to thank Neil McLaughlin, Lawrence Nichols, Julian Torelli, and two anonymous reviewers for their helpful feedback. Of course, a very special thanks goes to Dorothy Pawluch, without whom I could not have conceived of this paper in the first place.

\section{Declarations}

Conflict of Interest On behalf of all authors, the corresponding author states that there is no conflict of interest.

\section{References}

Abbott, A. (2001). Chaos of Disciplines. University of Chicago Press.

\footnotetext{
15 Perhaps this plea for a pragmatist framework will allow constructionist scholars to "get on with" analyses of social problems, instead of getting mired in the kind of ontological-epistemological debates I have engaged in here.
} 
Adorjan, M. (2013). Igniting Constructionist Imaginations: Social constructionism's absence and potential contributions to public sociology. The American Sociologist, 44(1), 1-22.

Adorjan, M. (2019). Social Constructionism Now More Than Ever: Following the Hermeneutic Money Trail in a Post-Truth World. The American Sociologist, 50, 160-174.

Adorjan, M., \& Kelly, B. (2008). Pragmatism and Engaged Buddhism: Working Toward Peace and a Philosophy of Action. Human Architecture: Journal of the Sociology of Self-Knowledge, 6(3), 37-49.

Adorjan, M., Christensen, T., Kelly, B., \& Pawluch, D. (2012). Stockholm Syndrome as Vernacular Discourse. The Sociological Quarterly, 53, 454-474.

Altheide, D. (2002). Creating Fear: News and the Construction of Crisis. Routledge.

Athens, L. (2015). Domination and Subjugation in Everyday Life. Transaction Publishers.

Best, J. (1993). But Seriously Folks: The Limitations of the Strict Constructionist Interpretation of Social Problems. In J. Holstein \& G. Miller (Eds.), Reconsidering Social Constructionism: Debates in Social Problems Theory (pp. 129-147). Routledge.

Blumer, H. (1971). Social Problems as Collective Behavior. Social Problems, 18(3), 298-306.

Bourdieu, P. (2004). Science of Science and Reflexivity. Harvard University Press.

Brewster, B., \& Puddephatt, A. (2016). George Herbert Mead as a Socio-Environmental Thinker. In H. Joas \& D. Huebner (Eds.), The Timeliness of George Herbert Mead (pp. 144-164). University of Chicago Press.

Burningham, K., \& Cooper, G. (1999). Being Constructive: Social Constructionism and the Environment. Sociology, 33(2), 297-316.

Catton, W., \& Dunlap, R. (1978). Environmental Sociology: A New Paradigm. The American Sociologist, $13,41-49$.

Chang, J.-Y. (2004). Mead's Theory of Emergence as a Framework for Multilevel Sociological Inquiry. Symbolic Interaction, 27(3), 405-427.

Choi, C. Q. (2017). "Gravitational Waves detected from Neutron-Star Crashes: The Discovery Explained," Space.com. Released October 16, retrieved March 29, 2021. http://www.space.com/ 38471-gravitational-waves-neutron-star-crashes-discovery-explained.html

Christensen, T. (2013). No Path to Paradise: Deconstructing the Promise of Public Sociology. The American Sociologist, 44(1), 23-41.

Christensen, T. (2019). Look Away: How the Social Constructionist Approach to Social Problems Channels Attention Away from the Marginalized. The American Sociologist, 50, 271-289.

Collins, H. (1985). Changing Order: Replication and Induction in Scientific Practice. Sage.

Collins, H. (2004). Gravity's Shadow: The Search for Gravitational Waves. University of Chicago Press.

Collins, H., \& Pinch, T. (1993). The Golem: What you should know about Science. Cambridge University Press.

Crawley, S. (2019). Reality Disjunctures and Epistemological Encampment: Addressing Relevance in Constructionist Perspectives on Social Problems. The American Sociologist, 50, 255-270.

Csillag, R. (2007). West Challenged by One of Its Own: Outspoken Convert to Islam says She's Still a Feminist, but Critics can't see Past the Hijab, Toronto Star, September 29, MET, p. L7.

Day, S. (2012). A Reflexive Lens: Exploring Dilemmas of Qualitative Methodology through the Concept of Reflexivity. Qualitative Sociology Review, 80(1), 60-85.

Dello Buono, R. A. (2013). Time to Change the Subject: A New Sociology of Praxis. Critical Sociology, 39(6), 795-799.

Dello Buono, R. A. (2015). Presidential Address: Reimagining Social Problems: Moving Beyond Constructionism. Social Problems, 62, 331-342.

Del Rosso, J. (2019). From Claims to Chains: The Materiality of Social Problems. The American Sociologist, 50, 247-254.

Farley and Geison (1974) Science, Politics, and Spontaneous Generation in Nineteenth Century France: The Pasteur-Pouchet Debate. Bulletin of the History of Medicine, 48(2), 161-98.

Giddens, A. (2011). The Politics of Climate Change, 2nd Edition. UK: Polity Press.

Gubrium, J., \& Holstein, J. (2012). Don't Argue with the Members. The American Sociologist, 43, 85-98.

Gusfield, J. (1984). On the Side: Practical Action and Social Constructivism in Social Problems Theory. In J. Schneider \& J. Kitsuse (Eds.), Studies in the Sociology of Social Problems (pp. 31-51). Ablex.

Habermas, J. (1987). The Theory of Communicative Action, Volume Two: Lifeworld and System: A Critique of Functionalist Reason. Boston, MA: Beacon Press.

Hazelrigg, L. (1985). Were it not for Words. Social Problems, 32(3), 234-237.

Huebner, D. (2014). Becoming Mead: The Social Process of Academic Knowledge. University of Chicago Press. 
Ibarra, P., \& Adorjan, M. (2018). Social Constructionism. In A. Trevino (Ed.), The Cambridge Handbook of Social Problems (pp. 279-300). Cambridge University Press.

Kuhn, T. (1962). The Structure of Scientific Revolutions. Chicago, IL: University of Chicago Press.

Latour, B. (1992). Where are the Missing Masses? Sociology of a Few Mundane Artifacts. In W. Bijker \& J. Law (Eds.), Shaping Technology, Building Society: Studies in Sociotechnical Change (pp. 225259). MIT Press.

Latour, B. (1993). We Have Never Been Modern. Harvard University Press.

Latour, B. (2005). Re-assembling the Social: An Introduction to Actor-Network Theory. Oxford University Press.

Latour, B., \& Woolgar, S. (1979). Laboratory Life: The Construction of Scientific Facts. Princeton University Press.

Lynch, M. (2000). Against Reflexivity as an Academic Virtue and Source of Privileged Knowledge. Theory, Culture, and Society, 17(3), 26-54.

Mannheim, K. (1929). Ideology and Utopia. Routledge and Kegan Paul.

McKinney, J. (1955). The Contribution of George H. Mead to the Sociology of Knowledge. Social Forces, 34(2), 144-149.

McVeigh, R. (2016). Mead, the Theory of Mind, and the Problem of Others. In H. Joas \& D. Huebner (Eds.), The Timeliness of George Herbert Mead (pp. 209-230). University of Chicago Press.

Mead, G. H. (1923). Scientific Method and the Moral Sciences. International Journal of Ethics, 23, $229-247$.

Mead, G. H. (1929). National Mindedness and International Mindedness. International Journal of Ethics, 39, 385-407.

Mead, G. H. (1932). Philosophy of the Present. University of Chicago Press.

Mead, G. H. (1934). Mind, Self and Society. University of Chicago Press.

Mead, G. H. (1938). Philosophy of the Act. University of Chicago Press.

Murphy, R. (1995). Sociology as if Nature did not Matter: An Ecological Critique. British Journal of Sociology, 46(4), 688-707.

Musolf, G. (1992). Structure, Institutions, Power, and Ideology: New Directions within Symbolic Interactionism. The Sociological Quarterly, 33(2), 171-189.

Nichols, L. (2003). Voices of Social Problems: A Dialogical Constructionist Model. Studies in Symbolic Interaction, 26, 93-123.

Nichols, L. (2015). Contextual Understanding in Constructionism: A Holistic, Dialogical Model. Qualitative Sociology Review, 11(2), 76-92.

Nissenbaum, H. (2010). Privacy in Context: Policy and the Integrity of Social Life. Stanford University Press.

Pawluch, D. (2019). On the Unbearable Lightness of Being a Constructionist. The American Sociologist, 50, 204-219.

Pfohl, S. (1977). The 'Discovery' of Child Abuse. Social Problems, 24, 310-324.

Pfohl, S. (1985). Toward a Sociological Deconstruction of Social Problems. Social Problems, 32(3), $228-232$.

Pollner, M. (1978). Constitutive and Mundane Versions of Labelling Theory. Human Studies, 1, $269-288$.

Pollner, M. (1987). Mundane Reason: Reality in Everyday and Sociological Discourse. Cambridge University Press.

Popper, K. (1959). The Logic of Scientific Discovery. Unwin Hyman.

Prus, R. (2007). The Intellectual Canons of Public Sociology: Pragmatist Foundations, Historical Extensions, and Humanly Engaged Realities. In L. Nichols (Ed.), Public Sociology: The Contemporary Debate (pp. 195-236). Transaction Publishers.

Prus, R. C., \& Puddephatt, A. J. (2009). "American Pragmatism: Examining Everyday Life in the Making," pp 69-92 in M.H. Jacobsen (ed.) Encountering the Everyday: An Introduction to the Sociologies of the Unnoticed. Palgrave MacMillan.

Puddephatt, A. (2005). Mead has Never Been Modern: Using Meadian Theory to Extend the Constructionist Study of Technology. Social Epistemology, 19(4), 357-380.

Puddephatt, A. (2008). George Herbert Mead: An Early Sociologist of Scientific Knowledge. Studies in Symbolic Interaction, 31, 31-60.

Puddephatt, A. (2009). The Search for Meaning: Revisiting Herbert Blumer's Interpretation of G.H. Mead. The American Sociologist, 40(1), 89-105.

Puddephatt, A. (2013). Finding G.H. Mead's Theory of Meaning through his Engagement with Key Intellectual Influences. In J. Low \& G. Bowden (Eds.), The Chicago School Diaspora (pp. 93-109). McGill-Queens University Press.

Rafter, N. (1992). Some Consequences of Strict Constructionism. Social Problems, 39(1), 38-39.

Schneider, J. (1985). Defining the Definitional Perspective on Social Problems. Social Problems, 32(3), $232-234$. 
Selg, P. (2013). The Politics of Theory and the Constitution of Meaning. Sociological Theory, 31(1), 1-23. Smith, J. (1963). The Spirit of American Philosophy. Oxford University Press.

Spector, M. (2019). Constructing Social Problems Forty Years Later. The American Sociologist, 50, $175-181$. Spector, M., \& Kitsuse, J. (1977). Constructing Social Problems. Menlo Park: Cummings.

Troyer, R. (1992). Some Consequences of Contextual Constructionism. Social Problems, 39(1), 35-37.

Williams, J. (2017). The Utility of Phenomenology in Understanding and Addressing Human-Caused Environmental Problems. In B. Brewster \& A. Puddephatt (Eds.), Microsociological Perspectives for Environmental Sociology (pp. 176-189). Routledge Press.

Wolf, A. (1991). Mind, Self, Society, and Computer. American Journal of Sociology, 96(5), 1073-1096.

Woolgar, S., \& Pawluch, D. (1985). Ontological Gerrymandering: The Anatomy of Social Problems Explanations. Social Problems, 32(3), 214-227.

Publisher's Note Springer Nature remains neutral with regard to jurisdictional claims in published maps and institutional affiliations. 